\title{
BMJ Open Cohort profile: the Chinese Pregnant Women Cohort Study and Offspring Follow-up (CPWCSaOF)
}

Tianchen Lyu (D) , ${ }^{1}$ Yunli Chen, ${ }^{1}$ Yongle Zhan, ${ }^{1}$ Yingjie Shi, ${ }^{1}$ Hexin Yue, ${ }^{1}$ Xuan Liu, ${ }^{1}$ Yaohan Meng, ${ }^{1}$ Ao Jing, ${ }^{1}$ Yimin Qu, ${ }^{1}$ Haihui Ma, ${ }^{2}$ Ping Huang, ${ }^{3}$ Dongmei Man, ${ }^{4}$ Xiaoxiu Li, ${ }^{5}$ Hongguo Wu, ${ }^{6}$ Jian Zhao, ${ }^{7}$ Guangliang Shan, ${ }^{8}$ Yu Jiang ${ }^{1}$

To cite: Lyu T, Chen Y, Zhan Y, et al. Cohort profile: the Chinese Pregnant Women Cohort Study and Offspring Followup (CPWCSaOF). BMJ Open 2021;11:e044933. doi:10.1136/ bmjopen-2020-044933

- Prepublication history for this paper are available online. To view these files, please visit the journal online (http://dx.doi org/10.1136/bmjopen-2020044933).

$\mathrm{TL}$ and $\mathrm{YC}$ contributed equally.

TL and YC are joint first authors.

Received 17 September 2020

Revised 20 January 2021

Accepted 04 March 2021

Check for updates

(C) Author(s) (or their employer(s)) 2021. Re-use permitted under CC BY-NC. No commercial re-use. See rights and permissions. Published by BMJ.

For numbered affiliations see end of article.

Correspondence to

Professor Yu Jiang;

jiangyu@pumc.edu.cn

\section{ABSTRACT}

Purpose A multicentre prospective cohort study, known as the Chinese Pregnant Women Cohort Study (CPWCS), was established in 2017 to collect exposure data during pregnancy (except environmental exposure) and analyse the relationship between lifestyle during pregnancy and obstetric outcomes. Data about mothers and their children's life and health as well as children's laboratory testing will be collected during the offspring follow-up of CPWCS, which will enable us to further investigate the longitudinal relationship between exposure in different periods (during pregnancy and childhood) and children's development.

Participants 9193 pregnant women in 24 hospitals in China who were in their first trimester (5-13 weeks gestational age) from 25 July 2017 to 26 November 2018 were included in CPWCS by convenience sampling. Five hospitals in China which participated in CPWCS with good cooperation will be selected as the sample source for the Chinese Pregnant Women Cohort Study (Offspring Followup) (CPWCS-OF).

Findings to date Some factors affecting pregnancy outcomes and health problems during pregnancy have been discovered through data analysis. The details are discussed in the 'Findings to date' section.

Future plans Infants and children and their mothers who meet the criteria will be enrolled in the study and will be followed up every 2 years. The longitudinal relationship between exposure (questionnaire data, physical examination and biospecimens, medical records, and objective environmental data collected through geographical information system and remote sensing technology) in different periods (during pregnancy and childhood) and children's health (such as sleeping problem, oral health, bowel health and allergy-related health problems) will be analysed.

Trail registration number CPWCS was registered with ClinicalTrials.gov on 18 January 2018: NCT03403543. CPWCS-OF was registered with ClinicalTrials.gov on 24 June 2020: NCT04444791.

\section{INTRODUCTION}

With the continuous development of the society and economy in China, the living standards of the Chinese population have improved, and the government and the public

\section{Strengths and limitations of this study}

- The main strength of the Chinese Pregnant Women Cohort Study (CPWCS) is its large sample size and long-term follow-up and its multicentre cohort that is representative of the population in China.

- The number of sample hospitals and participants in the Chinese Pregnant Women Cohort Study (Offspring Follow-up) is less than that in CPWCS, which may lead to bias and less representative cohorts.

- Maternal biospecimens were collected and biobanked only in one hospital of the 24 sites in CPWCS.

- The public in some areas in China consumes fluoridated drinking water, which has health effects on children and which is not assessed in the follow-up of children.

- Electronic cigarette and vaping are not assessed separately for cigarette use.

have paid more attention to maternal and child health. Key indicators such as maternal and infant mortality have been mentioned in China's 13th Five-Year Plan and the Healthy China Program (2019-2030), and the authorities have vowed to improve these. ${ }^{12}$

The hypothesis regarding the fetal origin of adult diseases was put forward by Barker, a British epidemiologist, in $1995 .^{3}{ }^{4}$ The hypothesis holds that a large part of the risk for adult metabolic diseases is determined by perinatal exposure. Increasing evidence supports the 'theory of developmental origin of health and disease (DOHaD), , conceding that the origin of disease may occur in fetal life. A large number of studies have shown that perinatal exposure has an impact on the growth and development of offspring. Children of pregnant women with obesity and gestational diabetes are more likely to have childhood metabolic syndrome ${ }^{6}$ which can lead to an increased risk of wheezing and asthma. ${ }^{7}$ Smith et al $l^{8}$ showed that there is a significant correlation between exposure to 
road traffic air pollution during pregnancy and birth weight. Reis $e t a t$ found that exposure to $\mathrm{PM}_{10}$ and $\mathrm{O}_{3}$ in the second and third trimesters of pregnancy may lead to low birth weight (LBW), with a dose-response relationship. Agay-Shay et $a l^{10}$ found that greening in residential areas has the strongest correlation with birth weight and LBW, which is consistent with the results of Laurent et al. ${ }^{11}$

Besides perinatal exposures, the effects of genetic factors and current living-related environmental exposures on children's growth and development have also been the focus of maternal and child health in recent years. Rask-Andersen $e a^{12}$ identified hundreds of genetic loci associated with body mass index (BMI) and risk of obesity. Individual genetic effects may vary from lifestyle or environmental factors and may be due to the interaction between genes and the environment. Epidemiological and experimental studies have shown that pregnancy and infancy are window periods that are particularly sensitive to the environment and can affect lifelong trajectories of health and disease. Nutrition, stress and toxicants induce epigenetic markers that may control long-term genetic expression patterns and can be transmitted from generation to generation. As a result, chronic diseases in adulthood, such as hypertension, diabetes and obesity, have early developmental origins in the perinatal period. The early interaction of the epigenome with other players (such as the microbiome) leads to significant variation in the biological susceptibility arising from the genome. ${ }^{13}$

Cohort studies play a significant role in maternal and child health research. Large-scale maternal and child cohorts have been established in some European countries in the late 20th century. Maternal and child cohort studies in China have also developed rapidly in recent years, and the construction of regional cohorts has been carried out in various parts of the country. However, with the wide application of emerging technologies, such as information sharing, establishing long-term cohorts with multicentre and multiregional cooperation in maternal and child health will become a trend. ${ }^{14} 15$ Therefore, a multicentre prospective cohort study, known as the Chinese Pregnant Women Cohort Study (CPWCS), was established in 2017 to collect and analyse the relationship between lifestyle during pregnancy and obstetric outcomes. Data on the life and health of mothers and their children as well as children's laboratory testing will be collected during the offspring follow-up of CPWCS, which will enable us to further investigate the longitudinal relationship between exposure in different periods (during pregnancy and childhood; exposure data during pregnancy have been obtained from the CPWCS, except for objective environmental exposure data) and children's development. We designed the Chinese Pregnant Women Cohort Study (Offspring Follow-up) (CPWCS-OF) to (1) establish a multicentre maternal and child cohort in China that can be followed up continuously, (2) provide comprehensive data on the health status of children in China, and (3) investigate the possible risk factors associated with child health that are present during the perinatal and early childhood periods, including genetic factors and environment-related exposures. This approach can provide prevalence and aetiology data, stimulate strategies for prevention of adverse health outcomes in early life, and promote further related research and evidencebased decision-making in the field of maternal and child healthcare in China.

\section{COHORT DESCRIPTION \\ Study design}

The Chinese Pregnant Women Cohort Study and Offspring Follow-up (CPWCSaOF) is a multicentre prospective cohort study consisting of Chinese Pregnant Women Cohort Study (CPWCS) and its Offspring Follow-up (CPWCS-OF). The study design and introduction of CPWCS have been reported in a previous study. ${ }^{16}$ Briefly, in CPWCS, pregnant women in their first trimester (5-13 weeks gestational age) from 25 July 2017 to 26 November 2018 were included by convenience sampling. Related information was collected by electronic self-administered questionnaires, including demographic information, living environment, and assessments of physical activity, dietary and nutritional factors, depression, sleep quality, and economic burden (see details in the 'Questionnaire for CPWCS' section). Subsequently, objective medical data, obstetric outcomes and neonatal outcomes were collected through the hospital information system (see details in the 'Medical records for CPWCS' section). Biospecimens were also collected in one sample hospital (see details in the 'Biospecimen collection for CPWCS' section).

CPWCS-OF was designed to further investigate the growth and development status of children in China and the associated factors. Mothers in CPWCS with their children meeting the inclusion criteria as mentioned in the 'Participant selection' section will be included in this follow-up. The participants will be asked to complete the electronic questionnaires about maternal and children's habits and health status (see details in the 'Questionnaire for CPWCS-OF' section). Environmental exposure assessment will be conducted to retrospectively collect objective outdoor environmental exposure data of participants before and during pregnancy (see details in the 'Environmental exposure assessment for CPWCS-OF' section), which can help elucidate the role of outdoor environment in pregnancy outcomes and long-term development of offspring. Laboratory testing of children, including biospecimen collection, and physical examination will be conducted to explore the interaction between genes and the environment (see details in the 'Physical examination and biospecimen collection for CPWCS-OF' section).

\section{Study sites}

CPWCS is set up by the School of Population Medicine and Public Health, Peking Union Medical College, in collaboration with the Peking Union Medical College Hospital. Twenty-four hospitals distributed across 15 


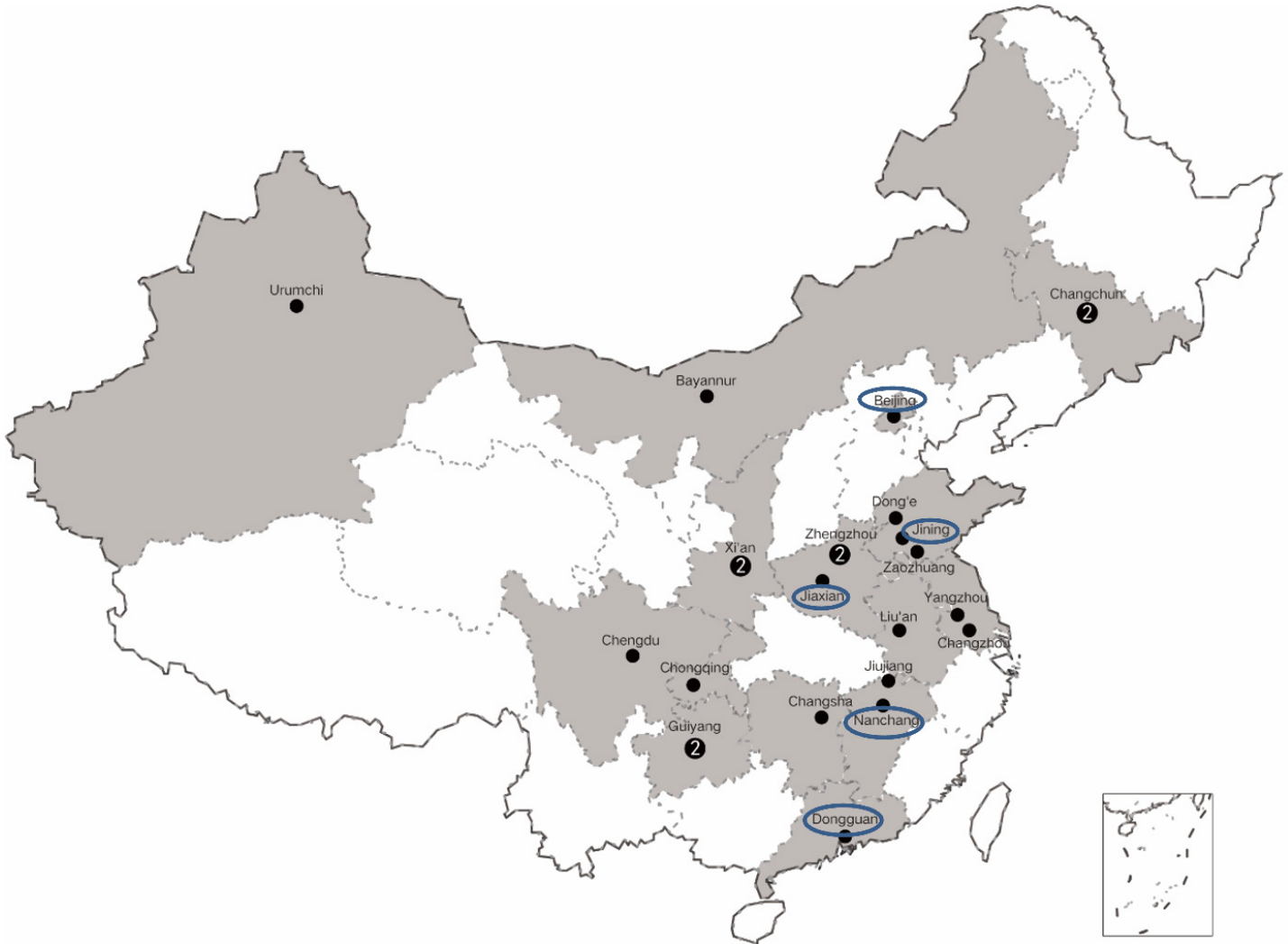

Figure 1 Locations of cohort sites of the Chinese Pregnant Women Cohort Study and Offspring Follow-up.

provinces (out of 34) in China (figure 1, table 1) were selected as the study sites after comprehensively considering geographical and economic factors, combined with the hospital's willingness to participate in the research. Among all hospitals, the Tongzhou Maternal and Child Health Hospital of Beijing was selected as the biospecimen subcohort study site, considering the technical and funding constraints.

CPWCS-OF is set up by the School of Population Medicine and Public Health, Peking Union Medical College, in collaboration with the School of Basic Medicine, Peking Union Medical College. Five hospitals in China (figure 1, table 1) that participated in CPWCS were selected as the sample source for CPWCS-OF. The following were the major considerations for study site selection: (1) data in CPWCS that are of high quality, including high accuracy and low missing rate; (2) good cooperation relationship between the hospital and the researchers, which could be beneficial for setting up a long-term and continuous follow-up; and (3) differing geographical locations and economic levels, which could improve the representativeness of the cohort.

\section{Participant selection}

The criteria for CPWCS have been reported in a previous study, ${ }^{16}$ while the criteria for CPWCS-OF are as follows:

- Inclusion criteria: (1) participation in CPWCS; (2) complete baseline data, first trimester data, delivery and neonatal outcomes available in CPWCS; (3) live birth and singleton in CPWCS; (4) willing to participate in CPWCS-OF; (5) able to complete the questionnaire; (6) residing in the study area; and (7) signed the informed consent form.

- Exclusion criteria: (1) persons not included in CPWCS; (2) incomplete baseline data, first trimester data, delivery or neonatal outcomes in CPWCS; (3) pregnancy outcomes in CPWCS were not singleton (abortion, stillbirth, twins, multiple births); (4) no longer residing in the study area; (5) death of the child; and (6) psychiatric diseases in mothers, precluding effective participation and cooperation in the study.

According to the inclusion and exclusion criteria, combined with the data of CPWCS, we expect to include approximately 2000 mother-child pairs in CPWCS-OF.

\section{Study procedure}

The study procedure for CPWCS is summarised in figure 2. Some details have been reported in a previous study. ${ }^{16}$

The study procedure for CPWCS-OF is summarised in figure 3. From five sample hospitals selected, mothers and their children who met the criteria for inclusion in CPWCS-OF were enrolled, and the data from CPWCS were matched by cohort code. Environmental exposure assessment technologies, such as geographical information system analysis and remote sensing technology, will be used to collect environmental exposure index before and during pregnancy retrospectively.

Participants will be contacted through a telephone number left with CPWCS to complete the follow-up 


\begin{tabular}{|c|c|c|c|c|}
\hline Code & Hospital name & Location & Region 1* & Region 2† \\
\hline 1 & Maternity and Children's Healthcare Centres in Urumchi & Urumchi, Xinjiang & North & West \\
\hline 2 & Guiyang Maternity and Child Health Hospital & Guiyang, Guizhou & South & West \\
\hline 3 & Northwest Women and Children's Hospital & Xi'an, Shaanxi & North & West \\
\hline 4 & Changsha Hospital for Maternal and Child Healthcare & Changsha, Hunan & South & Central \\
\hline 5 & The Third Affiliated Hospital of Zhengzhou University & Zhengzhou, Henan & North & Central \\
\hline 6 & Jiaxian Maternal and Child Healthcare Hospital & Jiaxian, Henan & North & Central \\
\hline 7 & Changzhou No.2 People's Hospital & Changzhou, Jiangsu & South & East \\
\hline 8 & Maternal and Child Healthcare Hospital of Jin'an District & Liu’an, Anhui & South & Central \\
\hline 9 & People's Hospital in Dong'e County of Shandong Province & Dong'e, Shandong & North & East \\
\hline 10 & Dongguan Maternal and Child Healthcare Hospital & Dongguan, Guangdong & South & East \\
\hline 11 & Bayannur Linhe District Maternal and Child Health Hospital & Bayannur, Inner Mongolia & North & West \\
\hline 12 & Affiliated Hospital of Guizhou Medical University & Guiyang, Guizhou & South & West \\
\hline 13 & Yangzhou Maternal and Child Health Hospital & Yangzhou, Jiangsu & South & East \\
\hline 14 & Affiliated Hospital of Jining Medical University & Jining, Shandong & North & East \\
\hline 15 & Zaozhuang Maternal and Child Health Hospital & Zaozhuang, Shandong & North & East \\
\hline 16 & China-Japan Friendship Hospital Affiliated Jilin University & Changchun, Jilin & North & Central \\
\hline 17 & Affiliated Hospital of Jiujiang Medical College & Jiujiang, Jiangxi & South & Central \\
\hline 18 & The First Affiliated Hospital of Nanchang University & Nanchang, Jiangxi & South & Central \\
\hline 19 & Chengdu Women's and Children's Central Hospital & Chengdu, Sichuan & South & West \\
\hline 20 & The Central Hospital of Three Gorges of Chongqing & Wanzhou, Chongqing & South & West \\
\hline 21 & Shaanxi Provincial People's Hospital & Xi'an, Shaanxi & North & West \\
\hline 22 & Xingyang Maternal and Child Health Hospital & Zhengzhou, Henan & North & Central \\
\hline 23 & Changchun Obstetrics-Gynaecology Hospital & Changchun, Jilin & North & Central \\
\hline 24 & Tongzhou Maternal and Child Health Hospital of Beijing & Tongzhou, Beijing & North & East \\
\hline
\end{tabular}

The hospital sites involved in CPWCS-OF are in bold.

${ }^{*}$ Region where participants were living in was categorised into North and South China according to the Qinling-Huaihe Line.

†Region where participants were living in was categorised into East, Central and West China according to the Chinese Health Statistics Yearbook.

CPWCSaOF, Chinese Pregnant Women Cohort Study and Offspring Follow-up; CPWCS-OF, Chinese Pregnant Women Cohort Study (Offspring Follow-up).

investigation. Children's demographic information, allergies and growth-related condition will be collected through questionnaires. Laboratory testing and abnormalities will be confirmed at the participating hospitals. The age distribution of children ranges from 9 to 24 months during the first follow-up. The second follow-up will be conducted 2 years later. All the collected data will be analysed to explore the risk factors for allergies and growth abnormalities in children.

For those who do not respond during the first time, a WeChat message, which is a social networking application that is widely used in China, will be sent to inform the participants. A short text message will be sent after 1 week to those who ignore the WeChat messages. A week before the deadline of follow-up, a telephone call to the mothers will be placed by trained investigators to reduce loss to follow-up.
Questionnaire data collection

Questionnaire for CPWCS

The electronic self-administered questionnaire for pregnant women is divided into seven sections: demographic information, living environment assessment, physical activity assessment, dietary and nutritional assessment, depression assessment, sleep quality assessment and economic burden (table 2).

\section{Demographic information}

A self-designed questionnaire has been developed by the coordinating centre, Peking Union Medical College, to obtain participants' demographic information, including hospital code, contact information, age, height, weight at presentation, current weight, education, occupation, ethnicity, personal annual income, family annual income, family member, husband's education, husband's occupation and other demographic data. 


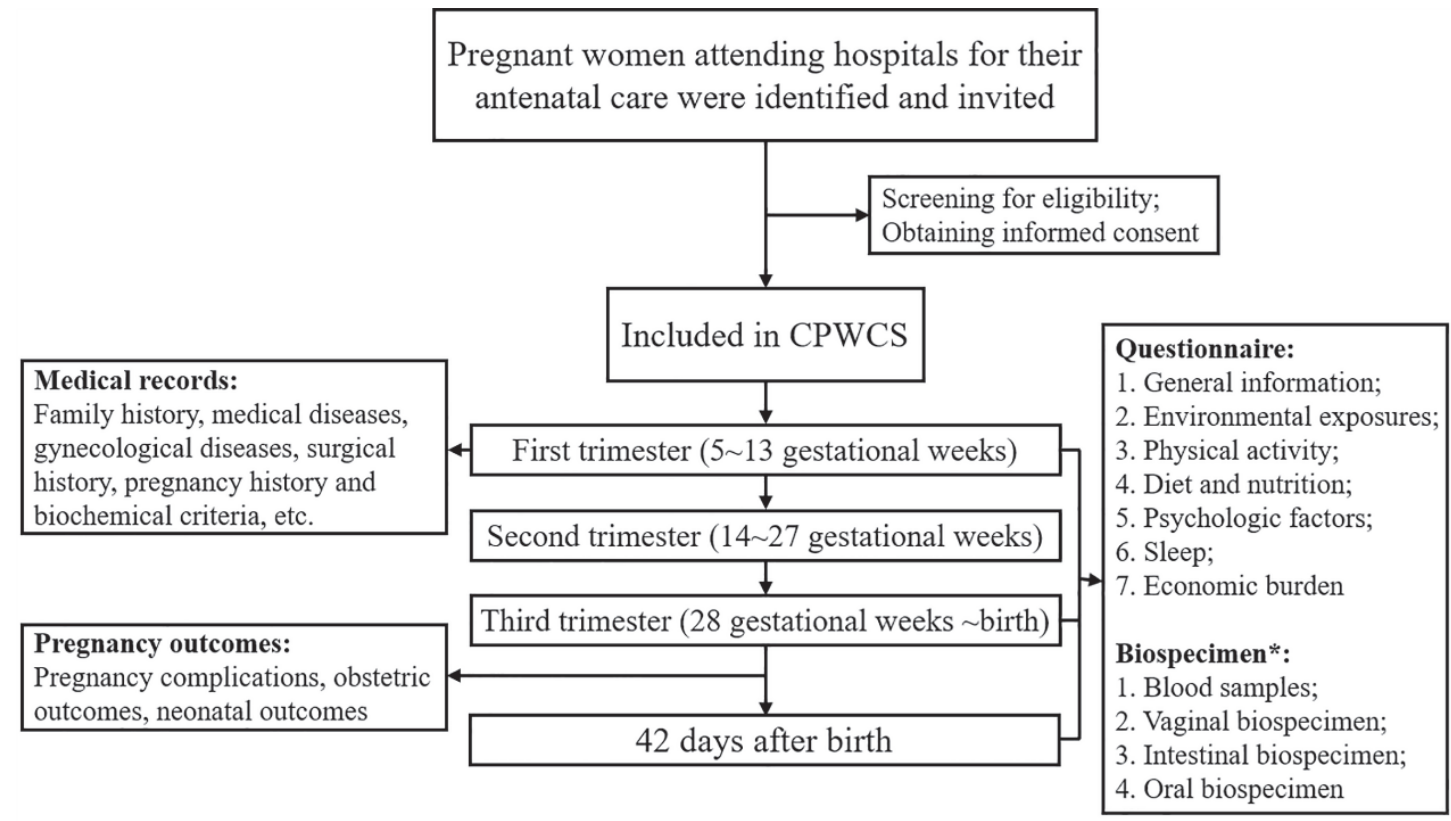

Figure 2 Study design and procedures for the Chinese Pregnant Women Cohort Study (CPWCS).

\section{Living environment assessment}

The following questions are asked to investigate the environmental exposure of the participants: 'How many cigarettes did you smoke per day before pregnancy'; 'How many cigarettes did you smoke per day in the past 30 days?'; 'Did you suffer passive smoking in the last 30 days?'; 'Did you cook in the past 30 days?'; 'Did you use a lampblack machine or a fan in the past 30 days?'; 'Which of the following potential pollution sources exists within 100 metres of your home: drainage ditch, garbage station, noise, chemical plant'; 'Which of the following substances have you been exposed to at home or in your workplace: pesticides, radiation, heavy metals such as lead, mercury, etc.'; 'Has your house been renovated within the last year?'; 'Has your workplace been renovated within the last year?'; 'How is the ventilation in your home?'

\section{Physical activity assessment}

The International Physical Activity Questionnaire has become the most widely used instrument for assessing physical activity. ${ }^{17}$ A meta-analysis confirmed its effectiveness, ${ }^{18}$ and it is available in two versions: long and short. The International Physical Activity Questionnaire-Short Form (IPAQ-SF) is recommended due to its simplicity and speed. ${ }^{19}$ It comprises seven questions that require participants to recall and record the frequency and time

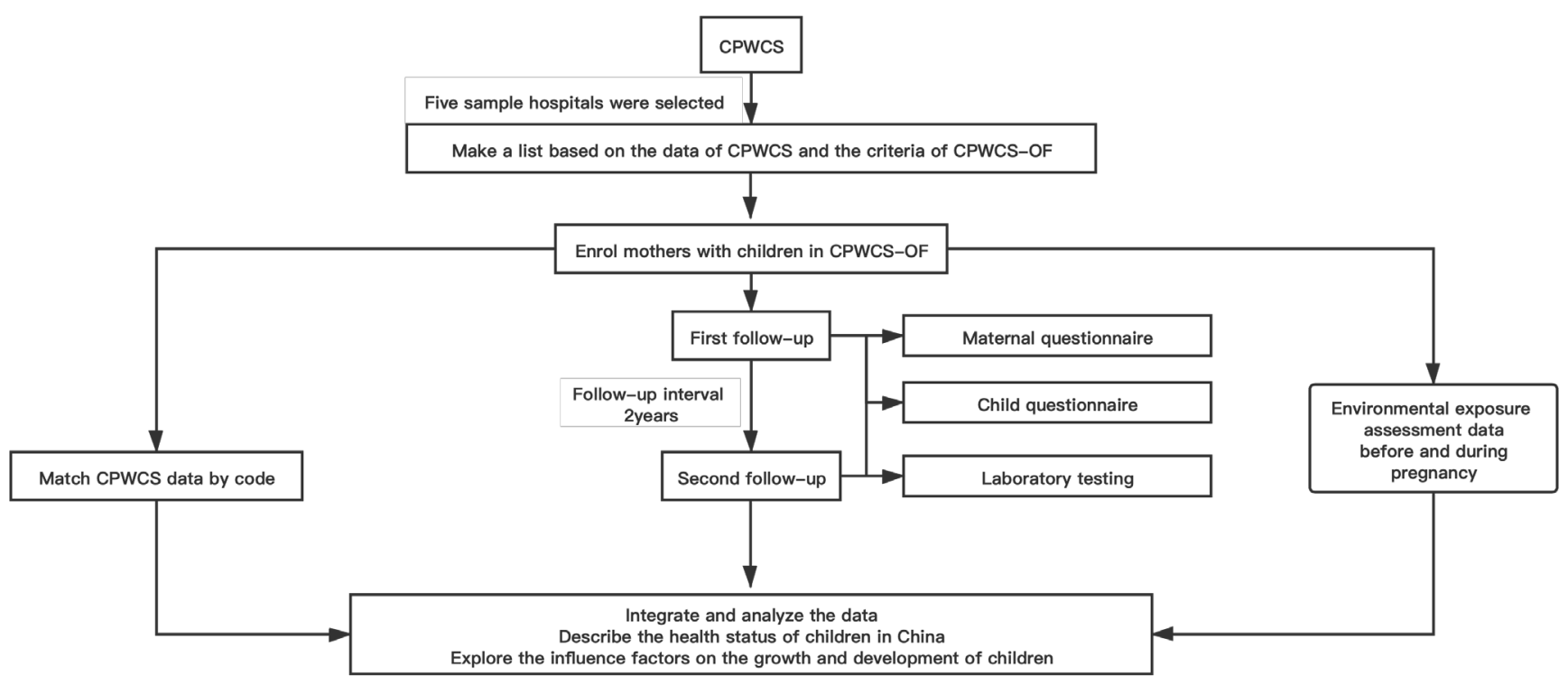

Figure 3 Study design and procedures for CPWCS-OF. CPWCS, Chinese Pregnant Women Cohort Study; CPWCS-OF, Chinese Pregnant Women Cohort Study (Offspring Follow-up). 
Table 2 Summary of questionnaire data collected in CPWCS

\begin{tabular}{|c|c|}
\hline Item & Information \\
\hline $\begin{array}{l}\text { Demographic } \\
\text { information }\end{array}$ & $\begin{array}{l}\text { Hospital code, contact information, age, } \\
\text { height, prepregnant weight, current weight, } \\
\text { education, occupation, personal income, } \\
\text { family income, family size, husband's } \\
\text { education, husband's occupation and other } \\
\text { demographic data. }\end{array}$ \\
\hline $\begin{array}{l}\text { Living } \\
\text { environment } \\
\text { exposure }\end{array}$ & $\begin{array}{l}\text { Smoking, passive smoking, indoor air } \\
\text { pollution, outdoor air pollution, noise } \\
\text { pollution, etc. }\end{array}$ \\
\hline $\begin{array}{l}\text { Physical } \\
\text { activity }\end{array}$ & $\begin{array}{l}\text { Sitting, walking, moderate activity and } \\
\text { vigorous activity from the International } \\
\text { Physical Activity Questionnaire-Short Form. }\end{array}$ \\
\hline $\begin{array}{l}\text { Diet and } \\
\text { nutrition }\end{array}$ & $\begin{array}{l}\text { Eating habits, cooking oil, vegetable, fruit, } \\
\text { meat, fish and shrimp, shellfish, dairy, } \\
\text { whole grains, beans and bean products, } \\
\text { fried food, fast food, sweets, nuts, puffed } \\
\text { food, carbonated beverages, sugary drinks, } \\
\text { wine, beer, liquor, nutrition supplement, etc } \\
\text { from a simple qualitative Food Frequency } \\
\text { Questionnaire. }\end{array}$ \\
\hline Depression & $\begin{array}{l}\text { Mood, pleasure, self-accusation, depression, } \\
\text { fear, insomnia, coping ability, sadness, crying } \\
\text { and self-injury from the Edinburgh Postnatal } \\
\text { Depression Scale. }\end{array}$ \\
\hline Sleep & $\begin{array}{l}\text { Sleep duration, sleep disturbance, sleep } \\
\text { latency, daytime dysfunction due to } \\
\text { sleepiness, sleep efficiency, overall sleep } \\
\text { quality and sleep medication use from the } \\
\text { Pittsburgh Sleep Quality Index. }\end{array}$ \\
\hline $\begin{array}{l}\text { Economic } \\
\text { burden }\end{array}$ & $\begin{array}{l}\text { Labour time, medical insurance, frequency } \\
\text { of seeking medical care, medical expense, } \\
\text { medical time, cost, etc. }\end{array}$ \\
\hline
\end{tabular}

CPWCS, Chinese Pregnant Women Cohort Study. of vigorous activity, moderate activity, walking and sedentary activity over the last 7 days. ${ }^{19}$ The Chinese version of the IPAQ-SF was used in this study, which exhibited intraclass correlation coefficients ranging from 0.81 to 0.89 , indicating good reliability and validity in the Chinese population. ${ }^{20}$

\section{Economic burden assessment}

The following questions are asked to investigate the economic status of the participants: 'Over the past 30 days, how many days did you work per week?'; 'How long do you work every day?', 'What is your medical insurance?'; 'How much of your expenses are reimbursed by your medical insurance?'; 'How many times have you been to the hospital in the past 30 days?'; 'How long did it take each time?'; 'How much do you spend on prenatal care on average each time'; 'How much is the average cost of going to the hospital each time?'; 'How many family members are required to go to the hospital with you each time?'

Details about dietary and nutritional assessment, depression assessment, and sleep assessment have been reported in a previous study ${ }^{16}$ and are listed in table 2.

\section{Questionnaire for CPWCS-OF}

The follow-up electronic questionnaires are divided into child and maternal questionnaires. The child questionnaire includes seven parts (table 3): demographic information, and assessments of feeding, sleep conditions, bowel health, oral development and parents' knowledge of child oral healthcare, early development, and physical health. The maternal questionnaire also includes seven parts (table 4): demographic information, and assessments of physical activity, dietary and nutritional status, smoking status, sleep conditions, psychological factors, and oral health. Trained investigators will use the telephone numbers left with CPWCS to contact the mothers who met the inclusion criteria and ask if they would like

Table 3 Summary of child questionnaire data collected in CPWCS-OF

Item Information

Demographic information Name, sex, date of birth, height and weight.

Feeding assessment Duration of breast feeding, supplementation of solid, semisolid or soft food (excluding liquids), and type of food consumed from WHO (Indicators for Assessing Infant and Young Child Feeding Practices) in 2010.

$\begin{array}{ll}\text { Sleeping assessment } & \begin{array}{l}\text { Sleep duration, nocturnal awakenings and methods of falling asleep during the past week } \\ \text { from the Brief Infant Sleep Questionnaire. }\end{array} \\ \begin{array}{l}\text { Bowel health assessment } \\ \begin{array}{l}\text { Oral development and parents' } \\ \text { knowledge of child oral } \\ \text { healthcare assessment }\end{array}\end{array} & \begin{array}{l}\text { Frequency, characteristics, difficulty and bowel movement habits. } \\ \text { Number of teeth, brushing time and frequency; dental caries and bad oral habits; judgement } \\ \text { of oralth-related problems. }\end{array} \\ \text { Ehys development assessment } & \begin{array}{l}\text { Simple movement and language expression, cognition and understanding from the } \\ \text { Developmental Surveillance Items of Child Health Pamphlet. }\end{array} \\ \text { Physicalth assessment } & \begin{array}{l}\text { Wheezing or whistle on the chest, asthma, sneezing, runny or stuffy nose, hay fever, itchy } \\ \text { rash, eczema, food allergies and other symptoms of allergy and duration. }\end{array}\end{array}$

CPWCS-OF, Chinese Pregnant Women Cohort Study (Offspring Follow-up). 
Table 4 Summary of maternal questionnaire data collected in CPWCS-OF

\begin{tabular}{|c|c|}
\hline Item & Information \\
\hline $\begin{array}{l}\text { Demographic } \\
\text { information }\end{array}$ & $\begin{array}{l}\text { Phone number, date of birth and current } \\
\text { weight. }\end{array}$ \\
\hline $\begin{array}{l}\text { Physical } \\
\text { activity } \\
\text { assessment }\end{array}$ & $\begin{array}{l}\text { Sitting, walking, moderate activity and vigorous } \\
\text { activity from the International Physical Activity } \\
\text { Questionnaire-Short Form. }\end{array}$ \\
\hline $\begin{array}{l}\text { Dietary and } \\
\text { nutritional } \\
\text { assessment }\end{array}$ & $\begin{array}{l}\text { Eating habits, cooking oil, vegetable, fruit, } \\
\text { meat, fish and shrimp, shellfish, dairy, } \\
\text { whole grains, beans and bean products, } \\
\text { fried food, fast food, sweets, nuts, puffed } \\
\text { food, carbonated beverages, sugary drinks, } \\
\text { wine, beer, liquor, nutrition supplement, etc } \\
\text { from a semiquantitative Food Frequency } \\
\text { Questionnaire. }\end{array}$ \\
\hline $\begin{array}{l}\text { Smoking } \\
\text { assessment }\end{array}$ & Smoking, frequency, quit time. \\
\hline $\begin{array}{l}\text { Sleeping } \\
\text { assessment }\end{array}$ & $\begin{array}{l}\text { Quality and quantity of sleep at night, feeling } \\
\text { during the day, accumulated sleep time from } \\
\text { the Athens Insomnia Scale. }\end{array}$ \\
\hline $\begin{array}{l}\text { Psychological } \\
\text { assessment }\end{array}$ & $\begin{array}{l}\text { Psychological emotional symptoms, physical } \\
\text { disorders, psychomotor disorders and } \\
\text { depression-related psychological disorder from } \\
\text { the Self-Rating Depression Scale. }\end{array}$ \\
\hline $\begin{array}{l}\text { Oral health } \\
\text { assessment }\end{array}$ & $\begin{array}{l}\text { Effects of oral problems on physical function, } \\
\text { psychological status and social activities from } \\
\text { the Oral Health Impact Profile-14. }\end{array}$ \\
\hline
\end{tabular}

CPWCS-OF, Chinese Pregnant Women Cohort Study (Offspring Follow-up).

to participate in CPWCS-OF. For those who orally agree to participate, the investigators will instruct them to sign an electronic informed consent form and finish the electronic child and maternal questionnaires.

\section{Child questionnaire}

\section{Demographic information}

A self-designed questionnaire including telephone number, mother's name, child's name, child's gender, date of birth, height, weight, and the mother's pregnancy and childbirth history will be asked. More detailed information about children had been collected during the neonatal outcomes investigation in CPWCS.

\section{Feeding assessment}

The feeding assessment questionnaire is based on the 2010 WHO report: Indicators for Assessing Infant and Young Child Feeding Practices. ${ }^{21}$ This guide provides tools for collection and calculation of indicators of infant and child feeding, as well as suggestions on adapting the survey to the appropriate context. Eight core and seven optional indicators are listed for the researchers. The questions are translated to Chinese and adapted to specific cultural factors, and are asked as follows: 'How long after birth did you first put the child to the breast (even if the baby did not suck the milk)?'; 'Did the child drink water or any other liquids besides breast milk within
6 months (183 days) after birth?'; 'At what age did the child stop breastfeeding?'; 'At what age did the child start adding food supplements?' Some questions should be answered according to the feeding situation in the last 24 hours: 'How many times yesterday, during the day or at night, did the child consume any solid, semi-solid or soft food (excluding liquid)?'; 'Did the child drink anything from a bottle with a nipple yesterday during the day or night?' Subsequently, the child is asked about drinking any kind of liquid in the last 24 hours, including infant formula or any kind of fresh animal milk, yoghurt, juice or juice drinks, clear broth, thin porridge, plain water, or any other liquids (written down in detail). The answer can be yes, no or unknown. The child's consumption of any kind of food in the last 24 hours is also asked, including grains, roots and tubers, dark green leafy vegetables, fruits rich in vitamin A, any other fruits and vegetables, organ meats, any meat, eggs, fish and seafood, beans or nuts or seeds, milk-based products, fats and oils, highsugar foods, condiments, or insects.

\section{Sleeping conditions assessment}

The Brief Infant Sleep Questionnaire (BISQ) has been validated for assessment of sleep quality for infants $0-3$ years of age. ${ }^{22}$ It was designed to evaluate sleep duration, night awakenings and methods of falling asleep in infants and young children during the past week. ${ }^{23}$ The Chinese version of the BISQ will be used in the study, which has shown acceptable test-retest reliability with correlation coefficients ranging from 0.439 to $0.848 .{ }^{23}$

\section{Bowel health assessment}

The types of stool are classified according to the Bristol scale $^{24}$ : (1) separate hard lumps, like nuts; (2) sausageshaped but lumpy; (3) like a sausage or snake, but with cracks on its surface; (4) like a sausage or snake, smooth and soft; (5) soft blobs with clear-cut edges; (6) fluffy pieces with ragged edges, a mushy stool; and (7) watery, no solid pieces. Pictures of the seven types of stool are shown to the mothers and the following question is asked: 'which picture describes your child's daily bowel movements over the past week?' To investigate children's bowel habits and their health, the following questions are also asked: 'How many times did the child have bowel movements per day over the past week?'; 'Which option describes the degree of difficulty in bowel movements of the child over the past week?'; 'Did your child have the following bowel problems recently?'; 'Did your child have bowel habits training? And if yes, when did it begin?'; 'Does your child exercise for more than 1 hour a day?'

\section{Oral development and parents' knowledge of child oral healthcare} assessment

The following questions are asked to investigate the oral development and hygiene habits of the children: 'How many teeth does your child have?'; 'Has your child started brushing their teeth?'; 'When did your child start brushing their teeth?'; 'How often does your child brush 
his/her teeth?'; 'What is the average time at which your child brushes their teeth?'; 'Does your child have tooth decay or caries?'; 'How many decayed teeth or caries does your child have?'; 'Was the tooth decay or caries managed at the hospital in time?'; 'Which of the following bad oral habits does your child have?'; 'Does your child go to see a doctor or dentist for oral problems other than tooth decay or caries-related issues?'; 'Does your child have a bottle or soother while sleeping?' Moreover, a table with several statements about oral healthcare will be presented to the mothers and they will be asked to judge if each statement is true or false. This is for the purpose of evaluating their awareness of oral healthcare issues.

\section{Early development assessment}

The Modified Checklist for Autism in Toddlers was revised by Robins et al in 2001 and is used worldwide for early screening of child autism. ${ }^{25}{ }^{26}$ It consists of 23 questions. The Chinese version will be used in this study, which has shown acceptable reliability and validity for Chinese children, with a Cronbach's alpha coefficient of 0.85 and a test-retest reliability coefficient total score of $0.77 .^{27}$ The Developmental Surveillance Items of Child Health Pamphlet is a Chinese tool developed by researchers in Taiwan for preventive care as part of the National Health Insurance System and has shown good reliability and validity in the Chinese population. ${ }^{28}{ }^{29}$ It comprises two to six questions for nine different ages and screens for developmental retardation in children.

\section{Physical health assessment}

The following questions will be asked to investigate allergy-related health problems in children: 'Have you been aware of wheezing or whistling in the child's chest in the last 12 months?'; 'In which months did the wheezing or whistling usually occur?'; 'How many times do you think your child has exhibited wheezing during these specific months in the last 12 months?'; 'Has your child been diagnosed with asthma in the last 12 months?'; 'Has your child ever had a problem with sneezing, or a runny or blocked nose in the absence of cold or the flu in the last 12 months?'; 'Has this nose problem been accompanied by itchy/watery eyes?'; 'In which months did your child have this nose problem in the last 12 months?'; 'How much did this nose problem interfere with your child's daily activities in the last 12 months?'; 'Has your child been diagnosed with hay fever in the last 12 months?'; 'Has your child ever had an itchy rash that subsided and recurred for at least 6 months?'; 'Has your child been diagnosed with eczema in the last 12 months?'; 'Has your child ever had any of the following symptoms after eating in the last 12 months?'; 'Has your child been diagnosed with food allergies in the last 12 months?'

\section{Maternal questionnaire}

Demographic information

A self-designed questionnaire that includes the telephone number, date of birth and current weight was used. More detailed information about mothers had been collected during the baseline investigation in CPWCS.

\section{Dietary and nutritional assessment}

A semiquantitative Food Frequency Questionnaire will be used in this study to investigate the frequency and average quantity of food consumed during the past 3 months. The foods were divided into 10 groups according to the Dietary Guidelines for Chinese Residents (2016), including grains, tubers, vegetables, fruits, meats, fish and seafood, eggs, bean products, nuts, and milk-based products. ${ }^{30}$ Energy and nutrient intake were calculated based on the Chinese Food Composition Tables. ${ }^{31}$ The frequency and average quantity of alcohol intake, juice intake and other drinks are also investigated in the questionnaire.

\section{Smoking assessment}

The questionnaire contains the question 'Do you smoke?', and according to the response the following questions will be asked, as appropriate: 'How many cigarettes do you smoke per day?' or 'How long have you quit smoking?'

\section{Sleeping conditions assessment}

The Athens Insomnia Scale (AIS) is a self-assessment tool for sleep difficulty based on the International Classification of Diseases-10. ${ }^{32}$ It consists of eight items on sleep quality and quantity at night and feelings during daytime. ${ }^{32}$ It has been proven to be reliable and valid for assessment and screening. ${ }^{33}$ The AIS Chinese version will be used in this study, and the questionnaire also asks about cumulative sleeping time at night and during daytime. The validity and reliability of the Chinese version of the AIS have been well tested in Hong Kong ${ }^{34}$ and Taiwan. ${ }^{35}$ A score of $\geq 6$ on the AIS English version is considered to indicate insomnia. ${ }^{33}$ However, studies from Hong Kong and Taiwan considered a score of 7 as the optimal cut-off for the Chinese version. ${ }^{34} 35$

\section{Psychological assessment}

The Self-Rating Depression Scale (SDS) is a widely used tool developed by Zung in $1965^{36}$ to assess depression in adults. It includes 20 questions comprising psychological and emotional symptoms, physical disorders, psychomotor disorders, and depression-related psychological disorders. The Chinese version of the SDS, which was first translated to evaluate the treatment efficacy of antidepressants in China and has shown acceptable reliability and validity, will be used in this study. ${ }^{37}$ The Self-Rating Anxiety Scale was developed by Zung in $1971^{38}$ and is a commonly used instrument for assessment of anxiety in adults. It has a similar form to the SDS with 20 questions and broad applicability for precise evaluation. The Chinese version, with correlation coefficients between each item and a total score of over 0.5 , is used in this study. ${ }^{39}$

\section{Oral health assessment}

The Oral Health Impact Profile-14 is a common instrument used to measure oral health-related quality of life. 
Table 5 Medical information collected from the hospital information system

\begin{tabular}{|c|c|c|}
\hline Study stage & Item & Information \\
\hline \multirow[t]{5}{*}{ Prenatal } & Family history & $\begin{array}{l}\text { High blood pressure, diabetes, hyperlipidaemia, stroke and malignant tumour, etc in first-degree } \\
\text { relatives (parents, brothers and sisters) and second-degree relatives. }\end{array}$ \\
\hline & $\begin{array}{l}\text { Gynaecological } \\
\text { diseases }\end{array}$ & $\begin{array}{l}\text { Endometriosis/adenomyosis, history of infertility, cervical lesions, uterine fibroids, ovarian cysts } \\
\text { and malignant gynaecological tumours. }\end{array}$ \\
\hline & Pregnancy history & $\begin{array}{l}\text { Pregnancy, birth, number of caesarean sections, number of vaginal deliveries, number of surgical } \\
\text { midwiferies, etc. }\end{array}$ \\
\hline & Metabolic index & Blood pressure, blood glucose, serum haemoglobin and urine protein and ketones. \\
\hline & $\begin{array}{l}\text { Pregnancy } \\
\text { complications }\end{array}$ & Gestational diabetes mellitus, pregnancy-induced hypertension, gestational anaemia, etc. \\
\hline \multirow[t]{2}{*}{ Delivery } & $\begin{array}{l}\text { Obstetric } \\
\text { outcomes }\end{array}$ & $\begin{array}{l}\text { Gestational age of delivery, vaginal delivery or caesarean section, stillbirth, fetal death and } \\
\text { miscarriage, abruptio placentae, premature rupture of fetal membranes, prolapse of cord. }\end{array}$ \\
\hline & $\begin{array}{l}\text { Neonatal } \\
\text { outcomes }\end{array}$ & $\begin{array}{l}\text { Apgar scores, low birth weight, macrosomia, small for gestational age, birth defect and neonatal } \\
\text { comorbidity (apnoea, infection, hypoglycaemia and neonatal intensive care unit admission). }\end{array}$ \\
\hline Post partum & & Puerperalism and feeding option. \\
\hline
\end{tabular}

It was designed to not only assess the physical impact of oral health, but also to comprehensively evaluate the effects of oral issues on physical function, psychological condition and social activity. ${ }^{40}$ The Chinese version will be used in this study, which has shown a Cronbach's alpha coefficient of 0.93 and intraclass correlation coefficients ranging from 0.53 to 0.71 , indicating good reliability and validity. ${ }^{41}$

IPAQ-SF will be used to assess physical activity as described in the pregnancy questionnaire.

\section{Medical records for CPWCS}

Table 5 illustrates the medical records that were collected at each stage of the CPWCS. Medical information collected by investigators from the hospital information system is entered in the electronic case report form. Specialised physicians are responsible for clinical diagnostic reports.

\section{Environmental exposure assessment for CPWCS-OF}

An assessment will be conducted to collect and analyse objective outdoor environmental exposure data of participants before and during pregnancy retrospectively in CPWCS, which will help elucidate the role of outdoor environment in pregnancy outcomes and long-term development of offspring. The environmental exposure indexes mainly include particulate matter $2.5\left(\mathrm{PM}_{2.5}\right)$, particulate matter $10\left(\mathrm{PM}_{10}\right)$, nitrogen dioxide $\left(\mathrm{NO}_{2}\right)$, sulfur dioxide $\left(\mathrm{SO}_{2}\right)$, ozone $\left(\mathrm{O}_{3}\right)$, temperature, humidity and green space coverage.

The specific calculation method is as follows: the longitude and latitude of each residential address which has been collected in the pregnancy questionnaire in CPWCS will be extracted, and geographical information system analysis can be used to estimate the monthly average concentrations of $\mathrm{PM}_{2.5}, \mathrm{PM}_{10}, \mathrm{NO}_{2}, \mathrm{SO}_{2}$ and $\mathrm{O}_{3}$ within $1 \mathrm{~km}$ of participants' baseline residence, as monitored by satellites. ${ }^{42}{ }^{43}$ Remote sensing technology will also be used to calculate the normalised difference vegetation index in the $500 \mathrm{~m}$ radius around participants' residential addresses to measure green coverage. ${ }^{44}$

Indexes needed, including accurate residential address and time when the mothers were investigated during pregnancy in CPWCS, have been collected in the pregnancy questionnaire. All retrospective data can be accessed on the websites of China Meteorological Data Service Centre, National Meteorological Information Centre (http:// data.cma.cn/), and the Institute of Remote Sensing and Digital Earth, Chinese Academy of Sciences (http://rs. ceode.ac.cn/).

\section{Laboratory testing}

\section{Biospecimen collection for CPWCS}

In the biospecimen subcohort, residual blood samples were collected after use from the hospital's Department of Clinical Laboratory. Sterile cotton swabs and vessels with Cary-Blair transport medium are used to collect vaginal, distal gut and saliva biospecimens.

Physical examination and biospecimen collection for CPWCS-OF Physical examination and biospecimen collection for children will be conducted as part of CPWCS-OF. In accordance with the requirements of the Chinese National Basic Public Health Service Specification (Third Edition), ${ }^{45}$ a trained physician or nurse practitioner will 
Table 6 Description of the baseline characteristics of the participants $(n=9193)$

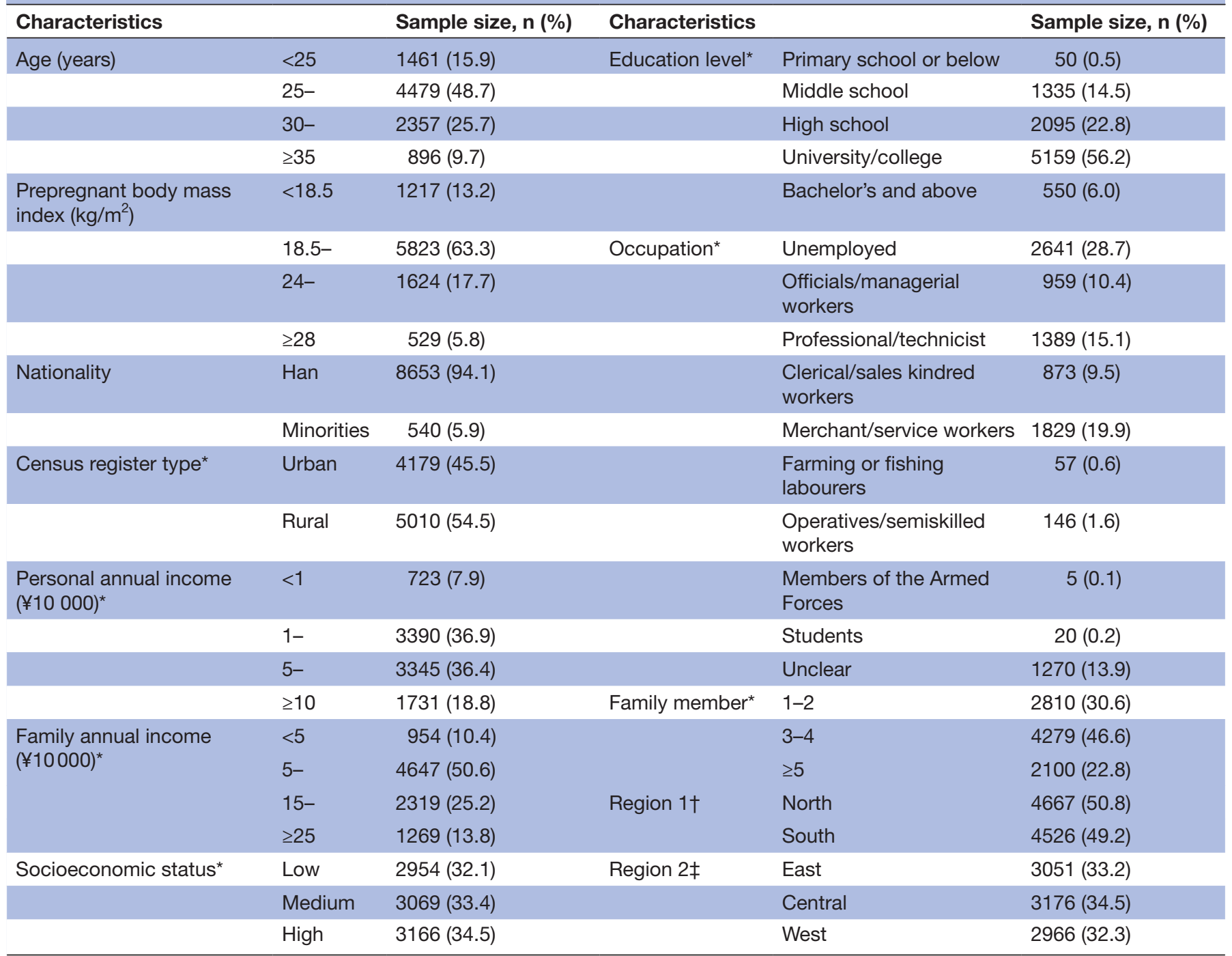

${ }^{*}$ Amount of missing data: 4.

†Region where participants were living in was categorised into North and South China according to the Qinling-Huaihe Line. †Region where participants were living in was categorised into East, Central and West China according to the Chinese Health Statistics Yearbook.

measure the height or length, weight, and head circumference of children according to standard operating procedures. In addition, findings on jaundice and fontanelle closure and related information will be collected from the Chinese Center for Disease Control and Prevention. Biological samples of children, such as blood, urine and saliva, will be collected by trained investigators. The growth and development of the oral cavity, hearing and vision will also be assessed. These measurements are part of routine medical screening of every child in China. Moreover, children's bone density and intellectual growth and development will be assessed and will be administered by a researcher. Bone density will be measured using quantitative ultrasound bone densitometer, which is commonly used in China. The Denver Developmental Screening Test ${ }^{46}$ will be used to assess children's bone density and intellectual growth and development. This method is suitable for infants and young children from 2 months to 6 years of age. Developmental delays or abnormalities in children can be detected at an early stage by evaluating the four domains of development: personalsocial, fine motor-adaptive, language and gross motor.

\section{Quality control}

Investigators will be uniformly trained to ensure the quality of data collection, and an investigator manual will be prepared to standardise the research process. An incentive system is implemented; only when participants complete two questionnaires of verified quality can they gain a small gift from the collaborative group. When filling in the two electronic questionnaires, a unique verification code sent by the system will be needed. The questionnaire cannot be filled in before automatic verification of the code, and it cannot be submitted until it is 
completely filled with no missing information. After the questionnaire is submitted, all information can be seen in the system simultaneously. Two quality control personnel will independently conduct a logical verification of the collected data. Once any logical errors are identified, they will promptly report this to the investigators, and the investigators will contact the participants in a timely manner to check and correct the errors. Quality control of the follow-up rate has been discussed in the 'Study procedure' section.

\section{Patient and public involvement}

Patients or the public were not involved in the design, or conduct, or reporting or dissemination plans of our research.

\section{FINDINGS TO DATE}

\section{Baseline characteristics of 9193 participants in CPWCS}

Between 25 July 2017 and 26 November 2018, a total of 10187 pregnant women attending hospitals for their antenatal clinic were identified and invited, and after screening for eligibility 9193 were enrolled. The baseline characteristics of the participants are shown in table 6 . The mean age of women was $28.5 \pm 4.3$ years (range: $16-50$ years) and the median BMI was $21.4 \mathrm{~kg} / \mathrm{m}^{2}$ (IQR: $\left.19.5-23.7 \mathrm{~kg} / \mathrm{m}^{2}\right)$. The median personal annual income was $¥ 50000$ (IQR: $¥ 30000$ - ¥80000), the median family annual income was $¥ 100000$ (IQR: ¥70000-¥200 000), and the median family member was 3 (IQR: 2-4). Moreover, $8653(94.2 \%)$ women were from the Han population, $5159(56.1 \%)$ women had college or university degree, and $5010(54.5 \%)$ women were rural residents. BMI was calculated as weight in kilograms divided by the square of height in metres $\left(\mathrm{kg} / \mathrm{m}^{2}\right)$. Socioeconomic status (SES) was assessed by Green's Socioeconomic Status Index based on education, occupation and annual family income: Green's three-factor SES index $=(0.5 \times$ education score $)+(0.3 \times$ occupation score $)+(0.3 \times$ family income score). ${ }^{47}$ The region where participants were living in was categorised into North and South China according to the Qinling-Huaihe Line, or into East, Central and West China according to the Chinese Health Statistics Yearbook.

\section{Major findings of CPWCS}

Using the data collected in CPWCS, we found that overweight and obesity before pregnancy and excessive weight gain during pregnancy are associated with developing gestational diabetes mellitus, gestational hypertension, large gestational age and macrosomia. ${ }^{16}$ We also found that dietary patterns were associated with gestational depression and sleep disturbance. Participants on plant-based dietary patterns have lower risk of gestational depression (OR, $0.66,95 \%$ CI 0.55 to 0.79 ) and sleep disturbance (OR, $0.80,95 \%$ CI 0.68 to 0.93 ), and similar results were observed in vitamin-rich dietary patterns (OR for depression: $0.46,95 \%$ CI 0.38 to 0.55 ; OR for sleep disturbance
$0.76,95 \%$ CI 0.65 to 0.89$)$. However, contrary results were found in high-fat dietary patterns (OR for depression 2.15, 95\% CI 1.25 to 1.85 ; OR for sleep disturbance 1.43 , $95 \%$ CI 1.22 to 1.67$).{ }^{48}$ The incidence rates of preterm birth (PB), LBW and small for gestational age (SGA) in pregnant participants in China were $4.76 \%, 3.53 \%$ and $5.74 \%$, respectively. In terms of $\mathrm{PB}$, the results of the analysis showed that gestational weight gain (GWG) and living in northern China were protective factors, while premature rupture of membranes, gestational hypertension, dental examination or treatment within 1-3 years and family of 3-4 members were risk factors. With respect to LBW, GWG and daily consumption of milk and dairy products were protective factors, while premature rupture of membranes, gestational hypertension, sedentary working time more than 6 hours, dental examination or treatment within 1-3 years and passive smoking were risk factors. For SGA, baby girl, passive smoking, peanut oil consumption and less salt intake were risk factors, while folic acid supplementation was a protective factor. ${ }^{49}$

\section{Author affiliations}

${ }^{1}$ Department of Epidemiology and Biostatistics, School of Population Medicine and Public Health, Chinese Academy of Medical Sciences and Peking Union Medical College, Beijing, China

${ }^{2}$ Department of Obstetrics, Tongzhou Maternal and Child Health Hospital of Beijing, Beijing, China

${ }^{3}$ Department of Nutrition, First Affiliated Hospital of Nanchang University, Nanchang, China

${ }^{4}$ Department of Obstetrics, Affiliated Hospital of Jining Medical University, Jining, China

${ }^{5}$ Department of Pediatric Gastroenterology, Dongguan Maternal and Child Health Care Hospital, Dongguan, China

${ }^{6}$ Department of Perinatal Health, Jiaxian Maternal and Child Health Care Hospital, Jiaxian, China

${ }^{7}$ Department of Nutrition and Food Safety, School of Population Medicine and Public Health, Chinese Academy of Medical Sciences and Peking Union Medical College,

Beijing, China

${ }^{8}$ Department of Epidemiology and Statistics, Institute of Basic Medical Sciences, Chinese Academy of Medical Sciences, Beijing, China

Acknowledgements The authors are extremely grateful to all the mothers and their children who participated in this study, as well as the entire CPWCSaOF team, including the researchers, investigators, lab technicians, statisticians, students and all those who contributed to this research.

Contributors Conceptualisation: YJ, GS and JZ. Methodology: TL and YC. Software: YZ and YS. Validation: HY and XL. Formal analysis: TL. Investigation: TL, HY, XL, YM, AJ, YC, YZ, YS, HM, PH, DMM, XL and HW. Resources: YM. Data curation: AJ and YQ. Writing-original draft preparation: TL, HY, XL, YM and AJ. Writing-review and editing: YZ, YC, YS and YQ. Visualisation: HY and TL. Supervision: YJ, GS and JZ. Project administration: YJ, GS and JZ. All authors have contributed to the composition of the cohort profile and have approved the final version of this manuscript to be published.

Funding This study was supported by an Innovation Fund for Medical Sciences of the Chinese Academy of Medical Sciences (2019-I2M-2-007). The funding agencies had no role in the design of the study, collection, analysis or interpretation of data, or in writing the manuscript.

Map disclaimer The depiction of boundaries on this map does not imply the expression of any opinion whatsoever on the part of BMJ (or any member of its group) concerning the legal status of any country, territory, jurisdiction or area or of its authorities. This map is provided without any warranty of any kind, either express or implied.

Competing interests None declared. 
Patient and public involvement Patients and/or the public were not involved in the design, or conduct, or reporting, or dissemination plans of this research.

Patient consent for publication Not required.

Ethics approval CPWCS-OF will be conducted according to the principles of the Declaration of Helsinki and was approved by the Ethics Review Committee of the Department of Scientific Research, School of Basic Medicine, Peking Union Medical College on 10 June 2019 (approval number: 2019043). The study was registered at ClinicalTrials.gov on 24 June 2020. An electronic informed consent will be obtained from participants prior to study commencement.

Provenance and peer review Not commissioned; externally peer reviewed.

Data availability statement Data are available upon reasonable request from the corresponding author.

Open access This is an open access article distributed in accordance with the Creative Commons Attribution Non Commercial (CC BY-NC 4.0) license, which permits others to distribute, remix, adapt, build upon this work non-commercially, and license their derivative works on different terms, provided the original work is properly cited, appropriate credit is given, any changes made indicated, and the use is non-commercial. See: http://creativecommons.org/licenses/by-nc/4.0/.

\section{ORCID iD}

Tianchen Lyu http://orcid.org/0000-0002-0981-3847

\section{REFERENCES}

1 The State Council, The People's Republic of China. Evaluation plan on 'Healthy China' released 2019.

2 National Health Commission of the People's Republic of China. Healthy China program (2019-2030) 2019.

3 Carpinello OJ, DeCherney AH, Hill MJ. Developmental origins of health and disease: the history of the Barker hypothesis and assisted reproductive technology. Semin Reprod Med 2018;36:177-82.

4 Gillman MW. Developmental origins of health and disease. N Engl J Med 2005;353:1848-50.

5 Hoffman DJ, Reynolds RM, Hardy DB. Developmental origins of health and disease: current knowledge and potential mechanisms. Nutr Rev 2017;75:951-70.

6 Boney CM, Verma A, Tucker R, et al. Metabolic syndrome in childhood: association with birth weight, maternal obesity, and gestational diabetes mellitus. Pediatrics 2005;115:e290-6.

7 Lodge CJ, Dharmage SC. Breastfeeding and perinatal exposure, and the risk of asthma and allergies. Curr Opin Allergy Clin Immunol 2016;16:231-6.

8 Smith RB, Fecht D, Gulliver J, et al. Impact of London's road traffic air and noise pollution on birth weight: retrospective population based cohort study. BMJ 2017;359:j5299.

9 Reis MMD, Guimarães MT, Braga ALF, et al. Air pollution and low birth weight in an industrialized City in Southeastern Brazil, 20032006. Rev Bras Epidemiol 2017;20:189-99.

10 Agay-Shay K, Peled A, Crespo AV, et al. Green spaces and adverse pregnancy outcomes. Occup Environ Med 2014;71:562-9.

11 Laurent O, Wu J, Li L, et al. Green spaces and pregnancy outcomes in Southern California. Health Place 2013;24:190-5.

12 Rask-Andersen M, Karlsson T, Ek WE, et al. Gene-environment interaction study for BMI reveals interactions between genetic factors and physical activity, alcohol consumption and socioeconomic status. PLoS Genet 2017;13:e1006977.

13 Simeoni U, Armengaud J-B, Siddeek B, et al. Perinatal origins of adult disease. Neonatology 2018;113:393-9.

14 Zhang M, Zheng YJ. [Characteristics related to maternal and child cohort studies in China: A review]. Zhonghua Liu Xing Bing Xue Za Zhi 2019;40:112-8.

15 Zhan YL, Yue HX, Shi YJ, et al. [Feasibility on the development of maternal and child cohorts, based on the maternal and child care network]. Zhonghua Liu Xing Bing Xue Za Zhi 2020;41:605-10.

16 Sun Y, Shen Z, Zhan Y, et al. Effects of pre-pregnancy body mass index and gestational weight gain on maternal and infant complications. BMC Pregnancy Childbirth 2020;20:1-13.

17 van Poppel MNM, Chinapaw MJM, Mokkink LB, et al. Physical activity questionnaires for adults. Sports Medicine 2010;40:565-600.

$18 \mathrm{Kim}$ Y, Park I, Kang M. Convergent validity of the International physical activity questionnaire (IPAQ): meta-analysis. Public Health Nutr 2013;16:440-52.

19 Lee PH, Macfarlane DJ, Lam TH, et al. Validity of the International physical activity questionnaire short form (IPAQ-SF): a systematic review. Int J Behav Nutr Phys Act 2011;8:115.
20 Deng HANB, Macfarlane DJ, Thomas GN, et al. Reliability and validity of the IPAQ-Chinese. Med Sci Sport Exerc 2008;40:303-7.

21 WHO, UNICEF, USAID, AED, UCDAVIS. Indicators for assessing infant and young child feeding practices (Part 2 measurement) 2010.

22 Sadeh A. A brief screening questionnaire for infant sleep problems: validation and findings for an Internet sample. Pediatrics 2004;113:e570-7.

23 Huang Y-S, Paiva T, Hsu J-F, et al. Sleep and breathing in premature infants at 6 months post-natal age. BMC Pediatr 2014;14:303.

24 Lewis SJ, Heaton KW. Stool form scale as a useful guide to intestinal transit time. Scand J Gastroenterol 1997;32:920-4.

25 Robins DL, Fein D, Barton ML, et al. The modified checklist for autism in toddlers: an initial study investigating the early detection of autism and pervasive developmental disorders. $J$ Autism Dev Disord 2001;31:131-44.

26 Mawle E, Griffiths P. Screening for autism in pre-school children in primary care: systematic review of English language tools. Int J Nurs Stud 2006;43:623-36.

27 Yuxing G, Jing L, Changjing L. Reliability and validity of the Chinese version of the modified checklist for autism in toddlers. Chinese Mental Health J 2011;25:409-14.

28 Huafang L, Aiwen H, Xianghui W. Brief introduction of reliability and validity of three child development screening scales in Taiwan area. Zhongguokangfu2013;28:403-7.

29 Huafang L, Lingyi Z, Wuxun X. A study on the reliability and validity of the development topic of child health Pamphlet. Taiwan Medicine 2008;12:502-12.

30 Chinese Nutrition Society. Dietary quidelines for Chinese residents. Beijing: People's Medical Pubilishing House, 20162016.

31 National Institute For Nutrition And Food Safety Of Chinese Center For Disease Control And Prevention. Chinese food composition table 2009. 2nd edn. Beijing: Peking University Medical Press, 2009.

32 Soldatos CR, Dikeos DG, Paparrigopoulos TJ. Athens insomnia scale: validation of an instrument based on ICD-10 criteria. $J$ Psychosom Res 2000;48:555-60.

33 Soldatos CR, Dikeos DG, Paparrigopoulos TJ. The diagnostic validity of the Athens insomnia scale. J Psychosom Res 2003;55:263-7.

34 Chung K-F, Kan KK-K, Yeung W-F. Assessing insomnia in adolescents: comparison of insomnia severity index, Athens insomnia scale and sleep quality index. Sleep Med 2011;12:463-70.

35 Sun J-L, Chiou J-F, Lin C-C. Validation of the Taiwanese version of the Athens insomnia scale and assessment of insomnia in Taiwanese cancer patients. J Pain Symptom Manage 2011;41:904-14.

36 Zung WWK. A self-rating depression scale. Arch Gen Psychiatry 1965;12:63-70.

37 Wang X, Wang X, Ma H. Mental health rating scale manual. Beijing: Chinese Mental Health Press, 1999.

38 Zung WWK. A rating instrument for anxiety disorders. Psychosomatics 1971;12:371-9.

39 Liu X, Tang M, Peng X. Factor analysis of the self-rating anxiety scale (SAS). Chinese J Nerv Mental Dis 1995;06:359-60.

40 Slade GD. Derivation and validation of a short-form oral health impact profile. Community Dent Oral Epidemiol 1997;25:284-90.

41 Xin W-ni, Ling J-qi, Weini X, Junqi L. [Validation of a Chinese version of the oral health impact profile-14]. Zhonghua Kou Qiang Yi Xue Za Zhi 2006;41:242-5.

42 Wang J, Li T, LV Y, et al. Fine particulate matter and poor cognitive function among Chinese older adults: evidence from a communitybased, 12-year prospective cohort study. Environ Health Perspect 2020;128:67013.

43 Lv Y, Zhou J, Kraus VB, et al. Long-term exposure to $\mathrm{PM}_{25}$ and incidence of disability in activities of daily living among oldest old. Environ Pollut 2020;259:113910.

$44 \mathrm{Ji}$ JS, Zhu A, Lv Y, et al. Interaction between residential greenness and air pollution mortality: analysis of the Chinese longitudinal healthy longevity survey. Lancet Planet Health 2020:4:e107-15.

45 China NHCotPsRo. National basic public health service specification. 3rd edn, 2017.

46 Frankenburg WK, Dodds J, Archer P, et al. The Denver II: a major revision and restandardization of the Denver developmental screening test. Pediatrics 1992;89:91-7.

47 Green LW. Manual for scoring socioeconomic status. Public Health Rep 1970;85:815-27.

48 Zhan $\mathrm{Y}, \mathrm{Ma} \mathrm{H}$, Feng $\mathrm{Y}$, et al. Dietary patterns in relation to gestational depression and sleep disturbance in Chinese pregnant women. J Obstet Gynaecol Res 2020

49 Shen ZZ, Wang YW, Ma S, et al. [Risk factors for preterm birth, low birth weight and small for gestational age: a prospective cohort study]. Zhonghua Liu Xing Bing Xue Za Zhi 2019;40:1125-9. 